\title{
E6/E7 proteins are potential markers for the screening and diagnosis of cervical pre-cancerous lesions and cervical cancer in a Chinese population
}

\author{
WEN-JING SHI ${ }^{1}$, HAO LIU $^{2}$, DAN WU $^{3}$, ZHEN-HUA TANG $^{3}$, YU-CHEN SHEN ${ }^{1}$ and LIN GUO $^{4}$ \\ ${ }^{1}$ Department of Clinical Laboratory, International Peace Maternity and Child Health Hospital, Shanghai Jiaotong University \\ School of Medicine, Shanghai 200030; ${ }^{2}$ Department of Health Technology and Informatics, Hong Kong Polytechnic \\ University, Hong Kong, SAR 999077; ${ }^{3}$ Department of Obstetrics and Gynecology, International Peace Maternity and Child \\ Health Hospital, Shanghai Jiaotong University School of Medicine, Shanghai 200030; ${ }^{4}$ Department of Clinical Laboratory, \\ Fudan University Shanghai Cancer Center, Shanghai Medical College of Fudan University, Shanghai 200032, P.R. China
}

Received October 6, 2015; Accepted March 14, 2017

DOI: $10.3892 / 01.2017 .6932$

\begin{abstract}
The present prospective study aimed to evaluate the effects of E6/E7 protein detection by western blotting on cervical cancer (CC) early screening compared with detection by Hybrid Capture 2 (HC2) test and ThinPrep cytological test (TCT) in a Chinese population. A total of 450 cases of cervical intraepithelial neoplasia (CIN) suspected samples (positive in $\geq 1$ indicator of TCT and HC2 test) were recruited from women who were treated at the International Peace Maternity and Child Health Hospital (Shanghai, China) from March 2014 to February 2015. Each sample was analyzed by cytological test. In addition, human papillomavirus (HPV) DNA examination by Hybrid Capture Tube test and E6/E7 protein expression detection by western blotting were performed in all samples, as well as histologic diagnosis to determine the stage of CIN. The results revealed that, for the diagnosis of $\mathrm{CIN}^{+}$, although the sensitivity of E6/E7 protein detection was lower than that of HC2 test (71.3 vs. $96.6 \%$, respectively), the specificity was markedly improved (67.6 vs. $5.9 \%$, respectively). Compared with that of TCT, the sensitivity of E6/E7 protein detection was much higher (36.2 vs. $71.3 \%$, respectively), but the specificity was lower (88.2 vs. $67.6 \%$, respectively). In the present study, HPV E6/E7 protein expression was evaluated as a potential new biomarker for CC, with satisfactory diagnostic values for HPV types 16 and 18. The relative diagnostic value may be further
\end{abstract}

Correspondence to: Professor Dan Wu, Department of Obstetrics and Gynecology, International Peace Maternity and Child Health Hospital, Shanghai Jiaotong University School of Medicine, 910 Hengshan Road, Xuhui, Shanghai 200030, P.R. China

E-mail: danwushanghai@sina.com

Key words: E6/E7 proteins, HPV DNA, HPV mRNA, prognostic detection, diagnosis improved by combination of E6/E7 messenger RNA detection.

\section{Introduction}

Cervical cancer (CC), which is the third most common cause of cancer in women in the world, is mainly associated with infection by human papillomavirus (HPV), which is a small, circular, double-stranded DNA virus that is also associated with cervical neoplasia, anogenital warts and other anogenital cancers $(1,2)$. According to previous reports from the International Agency for Research on Cancer, HPV could be classified into high-risk (HR) types (16, 18, 31, 33, 35, 39, $45,51,52,56,58,59,68,73$ and 82$)$, probable HR types $(26,53$ and 66) and low-risk types $(6,11,40,42,43,44,54,61,70,72$, 81 and CP6108) (3).

HR HPV, which is considered to be a necessary biological factor for $\mathrm{CC}$, can express specific viral genes such as E6 and E7, which have been observed in CC cell lines and biopsies $(4,5)$. These specific viral genes express oncoproteins (such as E6 and E7 proteins) that can be inserted into the host's cell genome (6). Therefore, E6 and E7 proteins may be critical for identifying HR HPV, and consequently could be a potential new biomarker for $\mathrm{CC}$ diagnosis.

Currently, the established methods for the screening of CC in clinical trials include Pap test, ThinPrep cytological test (TCT), HPV DNA determination by Hybrid Capture 2 (HC2) test, HPV messenger RNA (mRNA) determination by PreTectHPV-Proofer and colposcopy (7). However, due to the low sensitivity of the aforementioned methods, females with high risk of developing $\mathrm{CC}$ require regular re-tests to confirm the accuracy of the results (7). Among patients with negative cytology results but positive HPV DNA test results, a small percentage will develop CC (8). Therefore, an efficient diagnostic method is required for these particular patients $\left(\mathrm{TCT} / \mathrm{HPV}^{+}\right)$.

The present study aimed to evaluate E6/E7 proteins as the main biomarkers of pre-CC lesions, and to determine the suitability of E6/E7 protein detection as a potential screening method for CC diagnosis. 


\section{Materials and methods}

Subjects. A total of 450 samples from female patients with suspected cervical intraepithelial neoplasia (CIN) (positive in $\geq 1$ indicator of TCT and HC2 test, excluding carcinoma patients) according to routine physical examination were collected from the Cervical Department (International Peace Maternity and Child Health Hospital, Shanghai, China) from March 2014 to February 2015. Of these patients, 348 were diagnosed as CIN2 ${ }^{+}$and the rest were diagnosed as CIN2-. The patients were aged from 18 to 45 years old, and had not been subjected to any particular treatment, including hysterectomy, radiotherapy or chemotherapy. Each sample was analyzed by cytological test, HPV DNA detection by polymerase chain reaction and E6/E7 protein expression detection by western blotting $(9,10)$. In addition, histologic diagnosis was applied to determine the stage of CIN (11). Since histopathology is recognized as the gold standard for tumor diagnosis, the results of E6/E7 protein detection, HPV DNA evaluation and TCT were compared with the histopathologic results in terms of their sensitivity, specificity, positive predictive value (PPV) and negative predictive value (NPV) (11).

Preparation and preservation of samples. Cervical TCT samples obtained from biopsy were prepared in two formats, either using PreservCyt ${ }^{\circledR}$ Solution (Hologic Inc., Bedford, MA, USA) or SurePath ${ }^{\mathrm{TM}}$ Preservative Solution (TriPath Imaging Inc., Burlington, NC, USA). A total of $2 \mathrm{ml}$ cervical specimen preparation (containing $\sim 75 \mu \mathrm{l}$ cell pellets per $1 \mathrm{ml}$ solution) were collected in $20 \mathrm{ml}$ PreservCyt ${ }^{\circledR}$ Solution as specimens for TCT. All samples were maintained at $-20^{\circ} \mathrm{C}$ prior to use, and were tested within 1-2 weeks after collection. Specimens with abnormal TCT findings were rinsed into Specimen Transport Medium (Digene Corporation, Gaithersburg, MD, USA) to detect HPV DNA by Hybrid Capture Tube test (HCT; Digene Corporation) following the manufacturer's protocol for PreservCyt ${ }^{\circledR}$ Solution-containing specimens. The specimens were stored at $4^{\circ} \mathrm{C}$. The threshold of positive HPV detection was a relative light unit/cut-off ratio $(\mathrm{RLU} / \mathrm{CO})$ of $\geq 1.0$. Samples containing $<5 \mu \mathrm{l}$ cell precipitate were discarded.

TCT. TCT was used to identify high-grade squamous intraepithelial lesions (HSILs) (7). A liquid based cell plastic brush was inserted into the cervix at the squamo-columnar junction, and was rotated 5-8 circles. The exfoliated cells were stored in liquid-based cell preservation solution purchased from Beijing TCT Medical Technology Co., Ltd. (Beijing, China). The ultra-thin coating was made by ThinPrep 2000 system (Cytyc Corporation, Marlborough, MA, USA). The cells were fixed with $95 \%$ alcohol aqueous solution for $15 \mathrm{~min}$ at room temperature and pap stained for $3 \mathrm{~min}$ at room temperature, and then observed under the 15JF microscope (magnification, x40) from Shanghai CSOIF Co., Ltd. (Shanghai, China). Liquid-based cell plastic brushes and liquid-based cell preservation solution were purchased from Beijing TCT Medical Technology Co., Ltd. (Beijing, China). All steps (sample collection, preparation and final staining) were followed according to the manufacturer's protocol (Beijing TCT Medical Technology Co., Ltd.). The samples were classified into five grades according to The
Bethesda System: Within normal limitation (normal); atypical squamous cells with undetermined significance; low grade squamous intraepithelial lesion (LSIL); HSIL; and ASCs where HSIL cannot be excluded (12).

HC2 test. HC2 test (Qiagen Sciences, Inc., Gaithersburg, MD, USA), a signal amplification test based on the hybridization of a RNA probe cocktail for 13 high-risk oncogenic types with the target DNA, and capture and detection of the DNA-RNA hybrid by chemiluminescence, was applied to quantitate the level of HPV DNA for its standardization approved by the USA Food and Drug Administration (13). This test was performed with $4 \mathrm{ml}$ of PreservCyt samples, and then mixed with $400 \mu 1$ transfer buffer (digeneHC2HPVDNA detection kit; Qiagen Sciences, Inc.). Following centrifugation (135 x g for $15 \mathrm{~min}$ at $25^{\circ} \mathrm{C}$ ), $75 \mu \mathrm{l}$ of the supernatant was added to the microwell plate in a water bath at $65^{\circ} \mathrm{C}$ for $15 \mathrm{~min}$. The solution was mixed for $30 \mathrm{sec}$, and then kept in a water bath at $65^{\circ} \mathrm{Cfor} 15 \mathrm{~min}$. Denaturant $(150 \mu \mathrm{l}$; digeneHC2HPVDNA detection kit; Qiagen Sciences, Inc.) was then added to the mixture. Following TCT, the residual samples were denatured by asymmetric PCR (Piko ${ }^{\circledR}$ Thermal Cycler 96-well system; Thermo Fisher Scientific, Inc., Waltham, MA, USA) to obtain single-stranded DNA (13), which was then mixed and reacted with an RNA probe cocktail (BD Pharmingen; BD Biosciences, San Jose, CA, USA) for $13 \mathrm{HR}-\mathrm{HPV}$ oncogenic types $(16,18,31,33,35,39,45,51,52,56,58,59$ and 68$)$ to capture oncogenic HPV subtypes using DML-2000 gene hybridization amplifiers (Digene Corporation). The type of positive point HPV was determined according to the distribution pattern of HPV. RLU/CO values of $\geq 1.0$ were determined as positive. All samples were evaluated in triplicate.

Western blot assay. The human cervical cancer cells obtained from biopsy were frozen for 2 days. Protein extraction was performed from frozen cells by adding RIPA Rapid Cell Lysates (catalog no. BYL40825; Shanghai Jierdun Biotech Co., Ltd., Shanghai, China), which contained Halt Protease and Phosphatase Inhibitor Cocktail (Thermo Fisher Scientific, Inc.) as previously described (14). The protein concentration in the cell lysates was determined with Pierce BCA Protein Assay kit (catalog no. PICPI23223; Thermo Fisher Scientific, Inc.). A total of $25 \mu \mathrm{g}$ protein was loaded on $15 \%$ polyacrylamide gels, according to the molecular weight of E6/E7 proteins (HPV16 E6/E7 and HPV18 E6, 17 kDa; and HPV18 E7, $12 \mathrm{kDa}$ ), for electrophoresis as described previously (15). GAPDH was applied as an internal control to confirm equal loading of cell lysates. Upon electrophoresis, samples were transferred to polyvinylidene fluoride membranes and blocked with 5\% skimmed milk powder diluted in PBS-Tween-20 buffer. Next, primary antibodies (C1P5; catalog no., sc-460) against the E6/E7 proteins of HPV16 (HPV16 E6 dilution, 1:200; and HPV16 E7 dilution, 1:1,500), antibodies (BF7; catalog no., ab20192) against the E6 proteins of HPV18 or antibodies (8E2; catalog no., ab100953) against the E7 proteins of HPV18 (HPV18 E6; dilution, 1:600; and HPV18 E7 dilution, 1:1,000) for $1 \mathrm{~h}$ at room temperature were added, followed by addition of horseradish peroxidase-labeled secondary antibodies (dilution 1:1,000) incubated for $1 \mathrm{~h}$ at room temperature. All 
Table I. Characteristics of the patients according to histological diagnosis.

\begin{tabular}{lcc}
\hline Characteristic & CIN2 ${ }^{+}(\mathrm{n}=348)$ & CIN2- $(\mathrm{n}=102)$ \\
\hline Mean age \pm SD, years & $39.7 \pm 8.9$ & $42.2 \pm 9.7$ \\
HPV E6/E7 protein detection, n (\%) & & $33(32.4)$ \\
Positive & $248(71.3)$ & $69(67.6)$ \\
Negative & $100(28.7)$ & \\
HR-HPVHC2 test, n $(\%)$ & & $96(94.1)$ \\
Positive & $336(96.6)$ & $6(5.9)$ \\
Negative & $12(3.4)$ & $12(11.8)$ \\
TCT, n $(\%)$ & & $39(38.2)$ \\
HSIL & $126(36.2)$ & $6(5.9)$ \\
LSIL & $108(31.0)$ & $21(20.6)$ \\
ASC-H & $48(13.8)$ & $24(23.5)$ \\
ASC-US & $45(12.9)$ & $<0.001$ \\
Normal & $21(6.0)$ &
\end{tabular}

CIN, cervical intraepithelial neoplasia; SD, standard deviation; HPV, human papillomavirus; HC2, Hybrid Capture 2; TCT, ThinPrep cytological test; HSIL, high-grade squamous intraepithelial lesion; LSIL, low-grade squamous intraepithelial lesion; ASC, atypical squamous cell; US, undetermined significance; ASC-H, ASCs where HSIL cannot be excluded.

antibodies, together with anti-GAPDH antibody (6C5; catalog no., ab8245) were purchased from Abcam (Cambridge, UK), with the exception of anti-HPV16 E6 antibody, which was purchased from Santa Cruz Biotechnology, Inc. (Dallas, TX, USA). Subsequently, samples were subjected to enhanced chemiluminescence detection (GE Healthcare, Chicago, IL, USA). Finally, the representative gray value of protein expression was scanned (Fig. 1) and analyzed by Quantity One 1-D analysis software version 4.6.9 (Bio-Rad Laboratories, Inc., Hercules, CA, USA). Based on the positive/negative value of 1,393 volunteers from the Pap test between April 2012 and February 2015 in south China, the E6/E7 for the western blot analysis with an optical density under $450 \mathrm{~nm}$ value of $\geq 0.4 \pm 0.005$ were considered (16). The test was used to observe the exfoliated cells from the cervix fixed with physiological saline under the microscope.

Histological diagnosis. Histologic diagnosis, which is deemed as the gold standard for the diagnosis of $\mathrm{CC}$, was used in the present study to clarify the stage of CIN with CIN2+ serving as the disease endpoint (17). The main steps were performed according to the procedure described by Ratnam et al (17). Cervical biopsy results read by one or more pathologists were obtained from participating centers and accepted as the disease endpoint for the study purposes. Pathologists were blinded to HPV results.

Statistical analysis. Categorical variables were assessed in the form of percentages. Comparison among groups based on percentage values was assessed for statistical significance. Differences in the quantitative values (such as age) between groups were analyzed by the Student's t-test. Statistical analysis was performed by SPSS13.0 for Windows (SPSS, Inc., Chicago, IL, USA). $\mathrm{P}<0.05$ was considered to indicate a statistically significant difference.

\section{Results}

Results of histological diagnosis. The results from all four methods are shown in Table I. The proportion of E6/E7 protein-positive patients with $\mathrm{CIN} 2^{+}$was $>2$-fold higher than that of CIN2- patients, which was statistically significant $(\mathrm{P}=0.000)$. However, this high specificity was not observed in HC2-positive patients with high risk of developing $\mathrm{CC}$, although the sensitivity of the $\mathrm{HC} 2$ test was much higher than E6/E7 protein-positive patients (96.6 vs. 71.3\%). According to the results of TCT, only $\mathrm{HSIL}^{+}$cases were statistically significant $(\mathrm{P}<0.0001)$.

Comparison of diagnostic value of HPV E6/E7 proteins with other tests about sensitivity and specificity. For the diagnosis of $\mathrm{CIN}^{+}$cases in Table II, the specificity of E6/E7 protein detection was markedly improved compared with that of the HC2 test (67.6 vs. 5.9\%), although the sensitivity was lower (71.3 vs. 96.6). Compared with that of TCT, the sensitivity of E6/E7 protein detection was much higher (71.3 vs. $36.2 \%$ ), while the specificity was lower (67.6 vs. $88.2 \%$ ). According to previous studies, the sensitivity of E6 protein detection by OncoE6 Cervical Test was only $42.4 \%$, which is lower than the $71.3 \%$ of HPV E6/E7 protein detection, but it exhibited $99.1 \%$ specificity for E6 protein detection (18). The sensitivity of E6/E7 mRNA detection gradually increases when the number of HR-HPV types increases $(17,19,20)$. When the number of HR-HPV types was $>9$, the sensitivity was $>90 \%$, with a satisfactory specificity $(19,20)$. In addition, the sensitivity of HPV E6/E7 protein detection was higher than that of E6/E7 mRNA detection (71.3 vs. $56.3 \%$, respectively) with regard to HPV types 16 and 18 (19).

As shown in Table III, the specificity of E6/E7 protein detection for patients with CIN2+ plus ASC-US or LSIL was higher than that of HPV DNA testing, suggesting that 

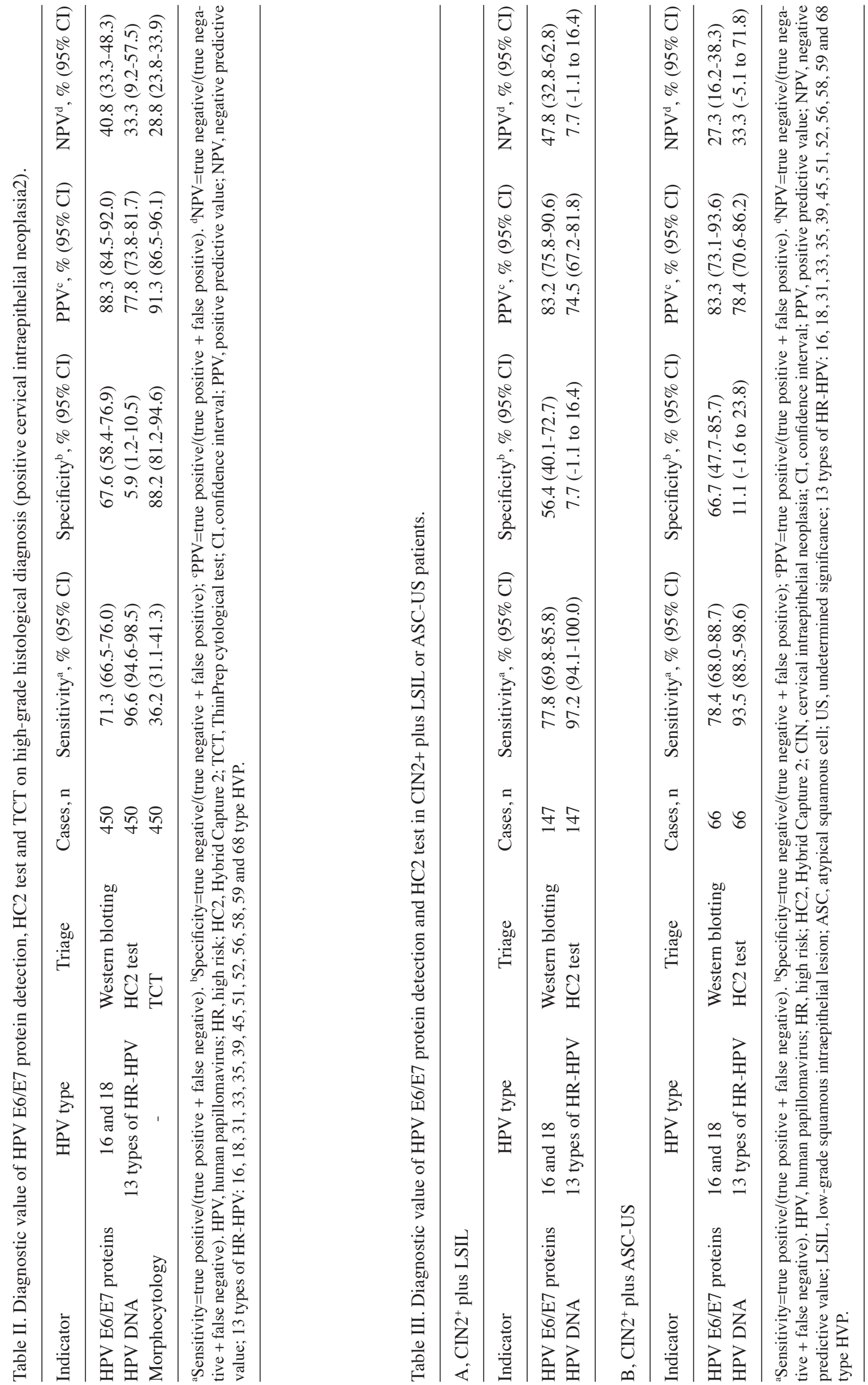
E6/E7 protein detection could be a critical adjuvant of HPV DNA testing and TCT. According to previous studies on HPV mRNA, the sensitivity and specificity of E6/E7 mRNA detection for patients with CIN2 ${ }^{+}$plus ASC-US or LSIL or ASC-US/LSIL were statistically similar for different types of HPV, ranging from 66.0 to $86.8 \%$, and from 52.2 to $82.0 \%$, respectively (21-23).

Previous evidence indicated that E6/E7 protein detection exhibited better sensitivity than TCT or E6/E7 mRNA detection for the same HPV types, and better specificity than HPV DNA testing by HC2. For CIN2 ${ }^{+}$plus ASC-US or LSIL cases, the sensitivity and specificity of E6/E7 protein detection were similar to those of E6/E7 mRNA detection for the same HPV types. However, markedly different results were obtained in terms of PPV and NPV (83.2 vs. $37.1 \%$ for PPV; and 47.8 vs. $88.9 \%$ for NPV, respectively) (23). Therefore, E6/E7 protein detection exhibited a higher PPV than that of E6/E7 mRNA detection. The sensitivity and specificity of E6/E7 protein detection for $\mathrm{CIN}^{+}$patients with HSIL and positive HPV DNA testing were 71.8 and $58.3 \%$, respectively (Table IV), while E6/E7 mRNA testing exhibited higher specificity and similar sensitivity compared with those of E6/E7 protein detection. According to previous studies on HPV mRNA detection, there may be no significant differences in terms of sensitivity or specificity between the screening indicators of E6/E7 mRNA and E6/E7 protein detection (21). However, the PPV in the E6/E7 protein test was higher than the NPV, while the NPV in the E6/E7 mRNA test was higher than the PPV.

\section{Discussion}

Approximately 565,000 new cases of CC occur in the world each year, and the incidence rate in developing countries is 3-fold higher than that in developed countries $(24,25)$. Approximately $50 \%$ of all CC cases in the world were recorded in China and India (26). Nearly 181,500 people are diagnosed with CC each year in China, while $>30,000$ women succumbed to CC (27). In Europe, 38,000 CC cases are diagnosed each year, and $>2 / 3$ of those would be expected to be cured and survive (28).

Usually, women with abnormal results of TCT or/and HPV DNA detection should undergo subsequent pathological biopsy in order to diagnose the existence and staging of CINs. Histology is recognized as the gold standard for diagnosing the pathological process of CC. CIN $2^{+}$is considered a precancerous lesion and, if left untreated, this may progress to cervical cancer; therefore, if a patient exhibits a CIN2 ${ }^{+}$ lesion, this should be treated $(17,29)$. However, it is unknown which kind of lesions will finally lead to infiltrative cancers. In developed countries, primary screening based on TCT could prevent $>80 \%$ of CC. Abnormal diseases are often missed or misdiagnosed due to the limitations of testing sensitivity and sampling techniques $(28,30)$.

As a result, numerous studies have focused on improving the techniques of CC screening. Chen et al (31) evaluated the efficacy of the Pap test combined with TCT in CC screening, and observed that the combination had high sensitivity and specificity. Subsequently, other reports revealed that the combined detection of HR-HPV by HC2 test and TCT may 


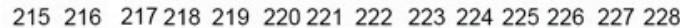

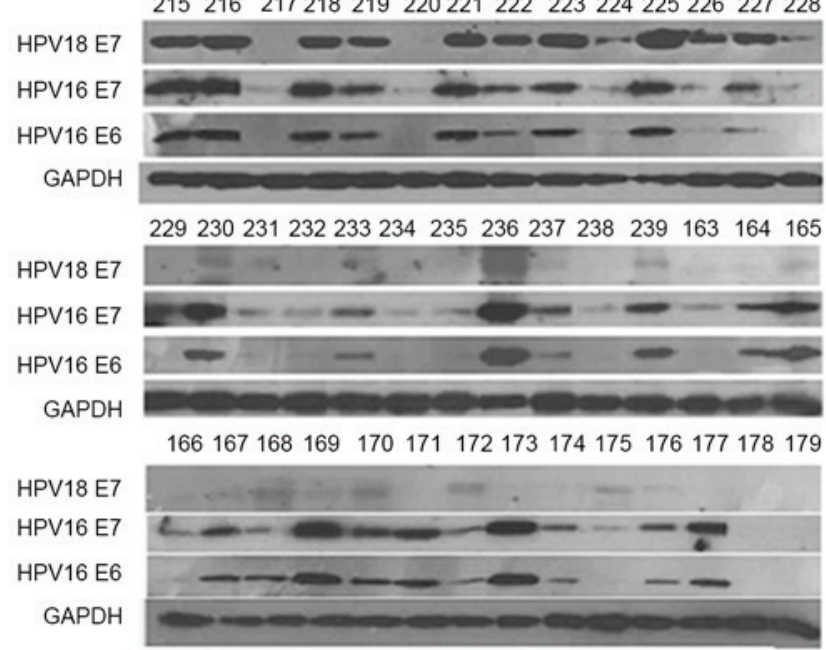

180181182183184185190191192193194195196197

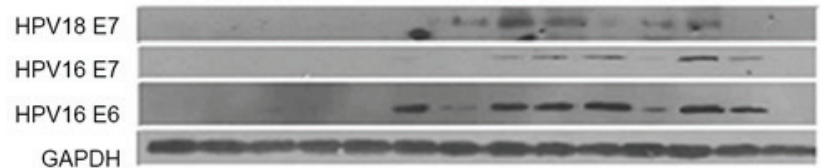

240241242243244245246247248249250251252253

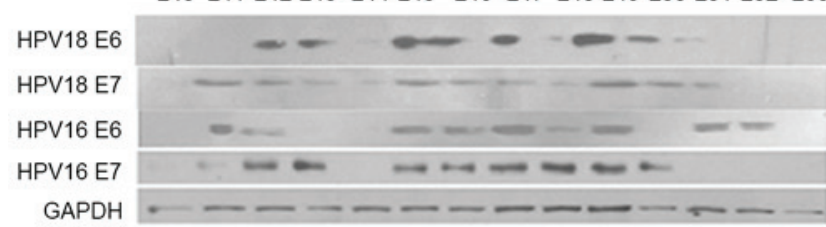

254255256257258259260261262263264265266267

HPV18 E6

HPV18 E7

HPV16 E6

HPV16 E7

GAPDH

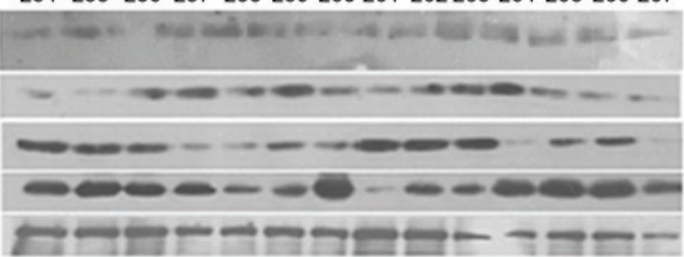

HPV18 E7

HPV16 E7

HPV16 E6

GAPDH

HPV18 E7

HPV16 E7

HPV16 E6

GAPDH

HPV18 E7

HPV16 E7

HPV16 E6

GAPDH

HPV18 E7

HPV16 E7

HPV16 E6

GAPDH

HPV18 E6

HPV18 E7

HPV16 E6

HPV16 E7

GAPDH

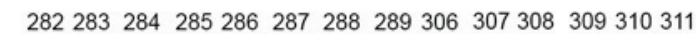

HPV18 E6

HPV18 E7

HPV16 E6

HPV16 E7

GAPDH

198199200201202203204205206207208209210211

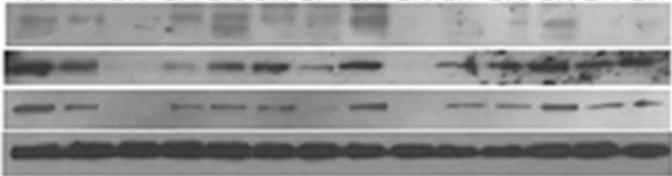

212213214140141142143144145146147148149150
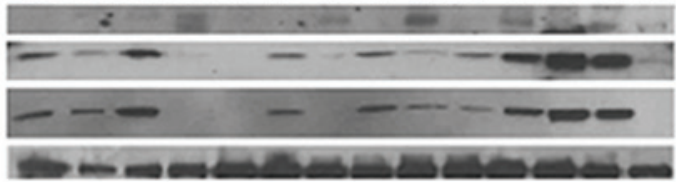

$151152 \quad 153154155156157158159160161162186187$

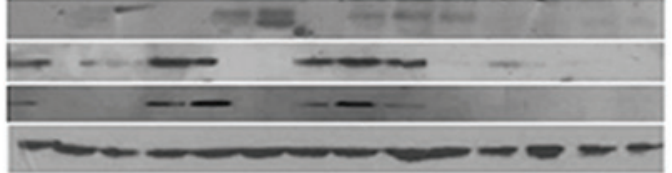

188189280291292293297298299300301302302304

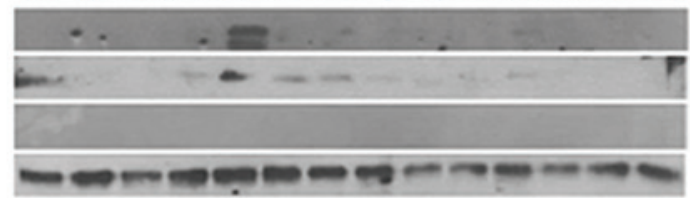

268269270271272273274275276277278279280281
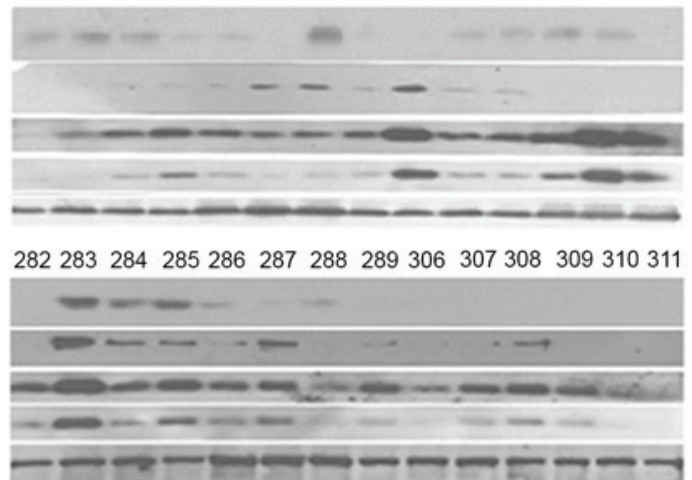

Figure 1. Representative image of HPV16/18 E6/E7 protein detection by western blotting with specific antibodies against E6/E7 proteins and GAPDH. HPV, human papillomavirus. Patients in the Pap test with positive results were detected for western blot analysis, and numbers represent patients.

improve the sensitivity and specificity of CIN diagnosis and the prediction of its postoperative recurrence (32). In 2010, Ratnam et al (17) assessed Proofer and HC2 tests in a cross-sectional study, and noticed that Proofer is more specific than $\mathrm{HC} 2$ in identifying women with $\mathrm{CIN} 2^{+}$, but has a lower sensitivity. The introduction of the above methods may improve the accuracy of CC screening, and may avoid a large number of unnecessary colposcopy and biopsy procedures, while effectively predicting the development of tumor lesions.

Although the aforementioned methods are popular and are recommended worldwide by guidelines for primary CC screening, a few potential patients are still missed and could not be dug out as detection of traditional activity showed lower sensitivity or specificity. Previous studies on the diagnosis of HPV and the occurrence of CC were usually conducted at the cellular, RNA or DNA level, with few studies performed at the protein level. Therefore, further evaluations are necessary for improved accurate screening.

In 2011, Ratnam et al (33) demonstrated that the sensitivity and specificity of the E6/E7 transcription-mediated amplification method for the detection of CIN2+ were 100.0 and $88.4 \%$, respectively, in a study comprising 1,373 women. The Aptima HPV test, which detected E6/E7 mRNA of 14 oncogenic types, was more specific for detecting CIN2 ${ }^{+}$than the HC2 test. However, in that study, Aptima and HC2 testing were performed upon routine $\mathrm{CC}$ screening, subjects of which were confirmed CIN2 ${ }^{+}$already (33). Following infection by HPV, HPV E6/E7 proteins would be overexpressed upon HPV invasion into the host's cervical cells in the form of episomal HPV DNA or upon viral integration into the host's genome (34). These events were closely and directly associated with the development of cancer; thus, the major cause of pre-CC lesions appears to be the functional expression of HR-HPV E6/E7 proteins $(34,35)$. Therefore, E6/E7 protein expression may be directly associated with CC risk.

A pilot clinical study on the application of OncoE6 Cervical Test indicated that HPV 16/18/45 E6 protein detection had higher specificity than HPV DNA testing for CIN3 ${ }^{+}$ detection (36). In another clinical trial, this new technology was demonstrated to have higher specificity compared 
with that of $\mathrm{HC} 2$ testing $[98.9 \%$; $95 \%$ confidence interval $(\mathrm{CI})=98.6-99.2 \%$ vs. $86.8 \%$; $95 \% \mathrm{CI}=85.9-87.7 \%$, respectively], but lower sensitivity $(67.3 \%$; $95 \% \mathrm{CI}=52.5-80.1 \%$ vs. 98.0\%; 95\% CI=89.1-99.9\%, respectively) for $\mathrm{CIN}^{+}$detection only (37). Based on those findings, the present study introduced a new type of biomarker, E6/E7 protein detection, and evaluated this new methodology for the diagnosis and progression determination of cervical pre-cancerous lesions and CC.

In the present study, the combination of E6 and E7 protein testing could enhance the accuracy of the test; thus, the differences between E6/E7 protein detection, HC2 test and TCT were assessed in a Chinese population. According to the present results, the application of E6/E7 protein detection in $\mathrm{CC}$ screening could reduce the limitations of other recent technologies, such as the Pap test and HC2 test, and the indicators (E6/E7 proteins) for both cervical pre-cancer and progression to $\mathrm{CC}$ could be quantified with the standard detection method established in the present study $(17,21)$. However, not all types of anti-E6/E7 monoclonal antibodies exhibit high specificity currently $(8,38)$. Therefore, further studies about the combination of E6/E7 mRNA and protein testing may be introduced to improve the specificity and sensitivity of CC screening. Further clinical studies with larger samples and multi-center studies are required to evaluate the efficiency of E6/E7 protein detection as a new indicator for the screening and diagnosis of CC.

In conclusion, the present study provided evidence that E6/E7 proteins may be potential new biomarkers with satisfactory diagnostic values for HPV types 16 and 18 . The relative diagnostic value may be further improved by combination with E6/E7 mRNA detection. Furthermore, the number of HPV types being tested could be increased in the future.

\section{Acknowledgements}

The authors would like to thank the patients, volunteers, clinicians and registry staff involved in the project, as well as the Natural Science Foundation of China (grant no. 09ZR1435000) for providing financial support.

\section{References}

1. Di Bonito $\mathrm{P}$, Grasso F, Mochi S, Accardi L, Donà MG, Branca M, Costa S, Mariani L, Agarossi A, Ciotti M, et al: Serum antibody response to human papillomavirus (HPV) infections detected by a novel ELISA technique based on denatured recombinant HPV16 L1, L2, E4, E6 and E7 proteins. Infect Agent Cancer 1: 6, 2006.

2. Chelimo C, Wouldes TA, Cameron LD and Elwood JM: Risk factors for and prevention of human papillomaviruses (HPV), genital warts and cervical cancer. J Infect 66: 207-217, 2013.

3. Muñoz N, Bosch FX, de Sanjosé S, Herrero R, Castellsagué X, Shah KV, Snijders PJ and Meijer CJ; International Agency for Research on Cancer Multicenter Cervical Cancer Study Group: Epidemiologic classification of human papillomavirus types associated with cervical cancer. N Engl J Med 348: 518-527, 2003.

4. DeCaprio JA: Human papillomavirus type 16 E7 perturbs DREAM to promote cellular proliferation and mitotic gene expression. Oncogene 33: 4036-4038, 2014.

5. Delury CP, Marsh EK, James CD, Boon SS, Banks L, Knight GL and Roberts $S$ : The role of protein kinase A regulation of the E6 PDZ-binding domain during the differentiation-dependent life cycle of human papillomavirus type 18. J Virol 87 : 9463-9472, 2013.
6. Ruttkay-Nedecky B, Jimenez Jimenez AM, Nejdl L, Chudobova D, Gumulec J, Masarik M, Adam V and Kizek R: Relevance of infection with human papillomavirus: The role of the p53 tumor suppressor protein and E6/E7 zinc finger proteins (Review). Int J Oncol 43: 1754-1762, 2013.

7. McGraw SL and Ferrante JM: Update on prevention and screening of cervical cancer. World J Clin Oncol 5: 744-752, 2014.

8. Zumbach K, Kisseljov F, Sacharova O, Shaichaev G, Semjonova L, Pavlova L and Pawlita M: Antibodies against oncoproteins E6 and E7 of human papillomavirus types 16 and 18 in cervical-carcinoma patients from Russia. Int J Cancer 85: 313-318, 2000

9. Chouhy D, Gil LB, Nocito AL, Wojdyla D, Ornella L, Cittadini J, Gardiol D and Giri AA: Development and evaluation of a colorimetric PCR system for the detection and typing of human papillomaviruses. Int J Mol Med 18: 995-1003, 2006.

10. Cheng J, Bian M, Cong X, Sun A, Li M, Ma L, Chen Y and Liu J: Evaluation of a novel real-time fluorescent polymerase chain reaction assay for high-risk human papilloma virus DNA genotypes in cytological cervical screening. Biomed Rep 1: 280-284, 2013.

11. Wu X, Chen G, Qiu J, Lu J, Zhu W, Chen J, Zhuo S and Yan J: Visualization of basement membranes in normal breast and breast cancer tissues using multiphoton microscopy. Oncol Lett 11: 3785-3789, 2016.

12. Paavonen J, Jenkins D, Bosch FX, Naud P, Salmerón J, Wheeler CM, Chow SN, Apter DL, Kitchener HC, Castellsague X, et al: Efficacy of a prophylactic adjuvanted bivalent L1 virus-like-particle vaccine against infection with human papillomavirus types 16 and 18 in young women: An interim analysis of a phase III double-blind, randomised controlled trial. Lancet 369: 2161-2170, 2007.

13. Pyne M, Law C, Hillyard D and Schlaberg R: Testing and genotyping of high-risk human papillomavirus by the cobas HPV Test and the Hybrid Capture 2 high-risk HPV DNA test using cervical and vaginal samples. J Clin Microbiol 52: 1720-1723, 2014.

14. Munagala R, Kausar H, Munjal C and Gupta RC: Withaferin A induces p53-dependent apoptosis by repression of HPV oncogenes and upregulation of tumor suppressor proteins in human cervical cancer cells. Carcinogenesis 32: 1697-1705, 2011.

15. Chen CL, Hsieh FC, Lieblein JC, Brown J, Chan C, Wallace JA, Cheng G, Hall BM and Lin J: Stat3 activation in human endometrial and cervical cancers. Br J Cancer 96: 591-599, 2007.

16. Perkins RB, Anderson BL, Gorin SS and Schulkin JA: Challenges in cervical cancer prevention: A survey of U.S. obstetrician-gynecologists. Am J Prev Med 45: 175-181, 2013.

17. Ratnam S, Coutlee F, Fontaine D, Bentley J, Escott N, Ghatage P, Gadag V, Holloway G, Bartellas E, Kum N, et al: Clinical performance of the PreTect HPV-Proofer E6/E7 mRNA assay in comparison with that of the Hybrid Capture 2 test for identification of women at risk of cervical cancer. J Clin Microbiol 48: 2779-2785, 2010

18. Zhao FH, Jeronimo J, Qiao YL, Schweizer J, Chen W, Valdez M, Lu P, Zhang X, Kang LN, Bansil P, et al: An evaluation of novel, lower-cost molecular screening tests for human papillomavirus in rural China. Cancer Prev Res (Phila) 6: 938-948, 2013.

19. Hovland S, Arbyn M, Lie AK, Ryd W, Borge B, Berle EJ, Skomedal H, Kadima TM, Kyembwa L, Billay EM, et al: A comprehensive evaluation of the accuracy of cervical pre-cancer detection methods in a high-risk area in East Congo. $\mathrm{Br}$ J Cancer 102: 957-965, 2010.

20. Waldstrøm M and Ornskov D: Clinical performance of a human papillomavirus messenger RNA test (Aptima HPV Assay) on residual material from archived 3-year-old PreservCyt samples with low-grade squamous intraepithelial lesion. Arch Pathol Lab Med 135: 1052-1056, 2011.

21. Benevolo M, Vocaturo A, Caraceni D, French D, Rosini S, Zappacosta R, Terrenato I, Ciccocioppo L, Frega A and Giorgi Rossi P: Sensitivity, specificity, and clinical value of human papillomavirus (HPV) E6/E7 mRNA assay as a triage test for cervical cytology and HPV DNA test. J Clin Microbiol 49: 2643-2650, 2011 .

22. Stoler MH, Wright TC Jr, Cuzick J, Dockter J, Reid JL, Getman D and Giachetti C: APTIMA HPV assay performance in women with atypical squamous cells of undetermined significance cytology results. Am J Obstet Gynecol 208: 144.e1-8, 2013. 
23. Perez Castro S, Iñarrea Fernández A, Lamas González MJ, Sarán Diez MT, Cid Lama A, Alvarez Martín MJ, Pato Mosquera M, López-Miragaya I, Estévez N, Torres Piñón J and Oña Navarro M: Human papillomavirus (HPV) E6/E7 mRNA as a triage test after detection of HPV 16 and HPV 18 DNA. J Med Virol 85: 1063-1068, 2013

24. Singh GK, Azuine RE and Siahpush M: Global inequalities in cervical cancer incidence and mortality are linked to deprivation, low socioeconomic status, and human development. Int J MCH AIDS 1: 17-30, 2012.

25. Knaul FM, Bhadelia A, Gralow J, Arreola-Ornelas H, Langer A and Frenk J: Meeting the emerging challenge of breast and cervical cancer in low- and middle-income countries. Int J Gynaecol Obstet 119 (Suppl 1): S85-S88, 2012.

26. Thun MJ, DeLancey JO, Center MM, Jemal A and Ward EM: The global burden of cancer: Priorities for prevention. Carcinogenesis 31: 100-110, 2010.

27. Lei T, Mao WM, Lei TH, Dai LQ, Fang L, Chen WQ and Zhang SW: Incidence and mortality trend of cervical cancer in 11 cancer registries of China. Chin J Cancer Res 1: 10-14, 2011.

28. Shepherd JH: Cervical cancer. Best Pract Res Clin Obstet Gynaecol 26: 293-309, 2012.

29. Sangoi AR, Rogers WM, Longacre TA, Montoya JG, Baron EJ and Banaei N: Challenges and pitfalls of morphologic identification of fungal infections in histologic, and cytologic specimens: A ten-year retrospective review at a single institution. Am J Clin Pathol 131: 364-375, 2009.

30. Jemal A, Siegel R, Ward E, Murray T, Xu J, Smigal C and Thun MJ: Cancer statistics, 2006. CA Cancer J Clin 56: 106-130, 2006.

31. Chen H, Shu HM, Chang ZL, Wang ZF, Yao HH, Zhu HM, Lu TM, Ma QY and Yang BL: Efficacy of Pap test in combination with ThinPrep cytological test in screening for cervical cancer. Asian Pac J Cancer Prev 13: 1651-1655, 2012.
32. Xu XY, Zhao W, Li GJ, Jin XY and Li YZ: Clinical significance of combined detection of thinprep cytology test and high risk human papillomavirus hybrid capture 2 assay in the screening and recurrence predication of cervical intraepithelial neoplasia. Zhonghua Yi Xue Za Zhi 92: 2503-2505, 2012 (In Chinese).

33. Ratnam S, Coutlee F, Fontaine D, Bentley J, Escott N, Ghatage P, Gadag V, Holloway G, Bartellas E, Kum N, et al: Aptima HPV E6/E7 mRNA test is as sensitive as Hybrid Capture 2 Assay but more specific at detecting cervical precancer and cancer. J Clin Microbiol 49: 557-564, 2011.

34. Peh WL, Middieton K, Christensen N, Nicholls P, Egawa K, Sotlar K, Brandsma J, Percival A, Lewis J, Liu WJ and Doorbar J: Life cycle heterogeneity in animal models of human papillomavirus-associated disease. J Virol 76: 10401-10416, 2002.

35. Bodily JM, Mehta KP, Cruz L, Meyers C and Laimins LA: The E7 open reading frame acts in cis and in trans to mediate differentiation-dependent activities in the human papillomavirus type 16 life cycle. J Virol 85: 8852-8862, 2011.

36. Schweizer J, Lu PS, Mahoney CW, Berard-Bergery M, Ho M, Ramasamy V, Silver JE, Bisht A, Labiad Y, Peck RB, et al: Feasibility study of a human papillomavirus E6 oncoprotein test for diagnosis of cervical precancer and cancer. J Clin Microbiol 48: 4646-4648, 2010.

37. Cuzick J, Bergeron C, von Knebel Doeberitz M, Gravitt P, Jeronimo J, Lorincz AT, J L M Meijer C, Sankaranarayanan R, J F Snijders P and Szarewski A: New technologies and procedures for cervical cancer screening. Vaccine 30 (Suppl 5): F107-F116, 2012.

38. Achour M, Ben Younes R, Kochbati L, Kahla S, Zeghal D, Maalej M, Zouari F and Oueslati R: Production of recombinant proteins GST L1, E6 and E7 tag HPV 16 for antibody detection of tunisian cervical cancer patients. African J Biotechnol 8: 369-374, 2009. 